\title{
POLYMER CHAIN ORDERING MANIFESTATION IN PHOTOLUMINESCENCE OF THIN F8BT FILMS
}

\author{
Bita GHASEMI, Jakub SEVCIK, Pavel URBANEK, Ivo KURITKA \\ Tomas Bata University in Zlín, University Institute, Centre of Polymer Systems, Zlín, Czech Republic, EU, \\ ghasemi@utb.cz
}

https://doi.org/10.37904/nanocon.2020.3687

\begin{abstract}
Poly(9,9-dioctyfluorene-alt-benzothiadiazole), F8BT, thin films were successfully deposited using spin coating and drop-casting methods on glass and silicon substrates. Films with thicknesses varying from tens to hundreds of nanometers were obtained as a result of variation in the deposition conditions, such as concentration or coating methods. The trends in manifestations of $0-0$ and $0-1$ vibronic transitions in UV-VIS absorption and photoluminescence (PL) spectra correlate with the thickness of the thin films. A threshold in the intensity ratio of the two transitions was observed at the thin film thickness about $250 \mathrm{~nm}$. The observed spectral features are interpreted in terms of the competitive effects of $\mathrm{J}$ - and $\mathrm{H}$ - aggregation of the macromolecular chains.
\end{abstract}

Keywords: F8BT, thin films, chain ordering, J- and H-aggregates, photoluminescence

\section{INTRODUCTION}

The possibility of processing the conjugated polymers to form useful and potent structure is the main advantage of polymeric organic semiconductors over non-polymeric organic semiconductors [1,2]. Conjugated polymers with various structures have been used in light-emitting diodes, photovoltaic cells, laser, and fieldeffect transistors mainly due to their absorption and electroluminescence feature. An important class of conjugated polymers are polyfluorenes that have attracted noticeable attention on the basis of their ease of spin coating or drop casting, and their ability to tune a wide range of optical and electronic properties. Poly (9,9di-noctylfluorene-alt-benzothiadiazole) (F8BT) is a yellowish-green light emitting copolymer with a high luminescence quantum yield $(60-80 \%)$, relatively high electron affinity, and large ionization potential which plays an important role as a host with electron transport [3-5]. According to previous reports on charge carrier mobilities and the time-of-flight studies on F8BT; however, the electron transport is dispersive, it is still the fastest charge carriers with mobility $\left(10^{-3} \mathrm{~cm}^{2} \mathrm{~V}^{-1} \mathrm{~s}^{-1}\right)$. Charge and energy transport in soft organic assemblies can be understood properly by considering the intermolecular (excitonic) coupling and electron-vibrational coupling using the concepts of $\mathrm{H}$-and $\mathrm{J}$-aggregation. Electronic interactions that occur either within a given chain or between chains stem from the aggregates of the conjugated polymer. J-aggregates (H-aggregates) occur when "head-to-tail" (side-by-side) orientations dominate. According to Kasha's work on the effect of molecular aggregation on the optical response, in J-aggregates ( $\mathrm{H}$-aggregates) the couplings are negative (positive), resulting in a spectral red shift (blue shift). But distinguishing these two aggregate types using the usual spectral shifts can be misleading. In case of poly(3-hexylthiophene) (P3HT), despite its H-aggregate nature, there is a considerable red shift which is attributed to improvement in intrachain planarization. The obtained information about the exciton bandwidth, the nature of disorder, and the exciton coherence length from the changes in the vibronic line strengths as a result of interaction are more distinguishing traits between these two types of aggregates [6-8]. Film thickness can impact on the microstructure of the thin conjugated polymer film and photoluminescence because of the various levels of manifestation of nonlocalized (aggregate states) and localized(intrachain) transitions. With increase of the thickness to some extent more ordered structure can be achieved and there is a thickness threshold in which the mesoscale (between nano-and micro- 
dimensions) effects such as self-healing mechanism will be revealed [10,11]. The effect of film thickness on optoelectrical properties and the correlation between the thickness and vibronic transition manifestations are presented in this study.

\section{EXPERIMENTAL PROCEDURES AND DETAILS}

Poly(9,9-dioctyfluorene-alt-benzothiadiazole), F8BT materials and toluene (p.a.) were purchased from SigmaAldrich and PENTA Czech Republic respectively and used without further purification. F8BT films were spin cast from toluene solutions with concentration ranging from $0.5 \%-3.0 \%$ to provide films with thicknesses varying from tens to hundreds of nanometers. To obtain films with thickness higher than $200 \mathrm{~nm}$, F8BT solutions with $1.5 \%$ and $3.0 \%$ concentrations were drop cast onto the prepared substrates. All substrates were cleaned by successive 12 min sonication in distilled water plus hellmanex, acetone and isopropyl alcohol, followed by UV ozone treatment for $10 \mathrm{~min}$. After deposition, the films were dried in vacuum furnace in $150{ }^{\circ} \mathrm{C}$ for 1 hour. The UV-Vis absorption spectra were recorded on a Perkin-Elmer Lambda 1050 Spectrometer. Fluorimeter FSL 920 from Edinburgh Instruments was used for the measuring of PL spectra. The thickness was measured by mechanical profilometer with $1 \mathrm{~nm}$ resolution (Bruker). The thickness of the F8BT films are shown in Table 1.

Table 1 Thickness of prepared F8BT films

\begin{tabular}{|c|c|c|c|c|c|}
\hline & \multicolumn{5}{|c|}{$\begin{array}{c}\text { Concentration } \\
(\% \mathrm{~W})\end{array}$} \\
\hline & $0.5 \%$ & $1.0 \%$ & $1.5 \%$ & $2.0 \%$ & $3.0 \%$ \\
\hline Spin speed & \multicolumn{5}{|c|}{ Thickness (nm) } \\
\hline 1000 rpm & 25 & 45 & 75 & 120 & 165 \\
\hline 2000 rpm & 20 & 27 & 47 & 75 & 118 \\
\hline 3000 rpm & 13 & 30 & 45 & 55 & 85 \\
\hline $4000 \mathrm{rpm}$ & 10 & 30 & 45 & 60 & 105 \\
\hline $5000 \mathrm{rpm}$ & 10 & 23 & 45 & 60 & 95 \\
\hline
\end{tabular}

\section{RESULTS AND DISCUSSION}

\subsection{UV-Vis spectroscopy}

The UV-Vis spectra of F8BT films with different thicknesses are depicted in Figure 1. It can be noted from the graph the main absorption peak is observed at $460 \mathrm{~nm}$. With an increase of thickness the absorption spectra show a tiny blue shift of maxima approximately $5 \mathrm{~nm}$ and the bands are broadened with increasing thickness. This may indicate the formation of a new energy state due to interchain aggregate states between polymer chains resulting in broadening of the absorption band [4]. On the other hand, one can expect that the formation of $\mathrm{H}$-aggregates, which are more favored in thicker films, broadens the absorption spectra toward longer wavelengths. This contradiction can be

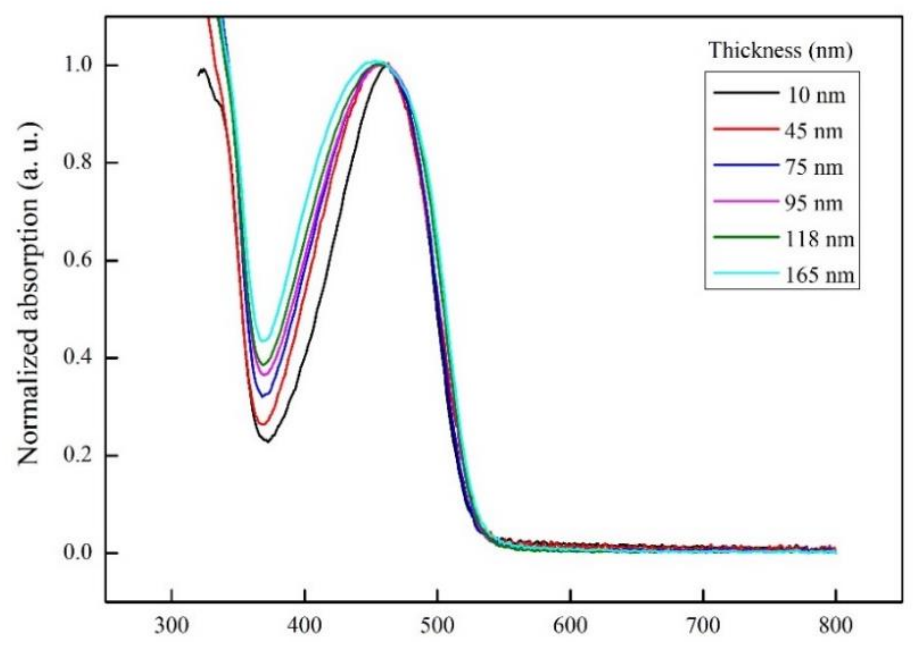

Figure 1 UV-Vis spectra of F8BT with different thicknesses on glass substrates 
explained by $\mathrm{JH}$-aggregates creation, where the interplay of these two aggregation modes results in the broadening toward higher energies. Similar explanation is introduced in [4], where it is described as alternating m-stacking of polymer chains.

\subsection{Photoluminescence (PL) spectroscopy}

The representative room temperature photoluminescence (PL) spectra of F8BT films are illustrated in Figure 2. From the graph, it can be seen that 0-0 peak is slightly red-shifted with increasing thickness. The spectral intensity for the second peak 0-1 relatively increases with increasing thickness. The 0-0 PL transition of the thinnest film is situated at $537 \mathrm{~nm}$. For the thicker films up to $200 \mathrm{~nm}$, the emission maxima of 0-0 transition are shifted towards $545 \mathrm{~nm}$. For the films with a thickness higher than $200 \mathrm{~nm}$, the 0-0 transitions are disappeared from the spectrum, and the 0-1 transition is prevailing. The shift of 0-0 transition can be attributed to a change of polymer chain packing [4], where the J-aggregation of chains supports this transition. Nevertheless, with increasing thickness, the

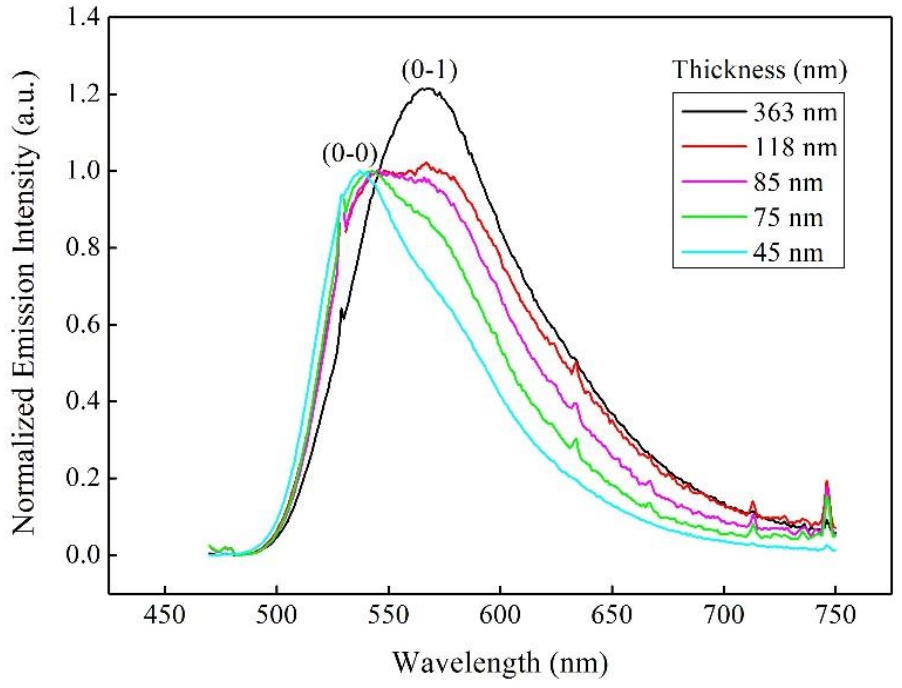

Figure 2 Emission spectra of F8BT with different thicknesses on silicon substrates $\lambda_{\mathrm{ex}}=460 \mathrm{~nm}$. polymer chains can form a film with a more organized structure, and thus the $\mathrm{H}$-aggregation with alternating $\pi$-stacking of polymer chains is more favorable and changes the spectral features of the material. For the thickest films, the structural ordering of chains causes prevailing 0-1 with longer conjugation length resulting in low energy radiative states $[4,10]$.

As emission spectra, excitation spectra can be analyzed in the same framework. The positions of excitation maxima and the shape of excitation spectra are influenced by the thickness of the films as illustrated in Figure 3. A slight blue shift and considerable broadening of these peaks are obvious with increasing thickness varying from $45 \mathrm{~nm}$ to $120 \mathrm{~nm}$. In the case of the thickest film, significant change of spectrum shape and redshift of excitation maxima were observed. These phenomena can be plausibly explained by extension of conjugation length whereas the longer is the length of conjugated segments the higher delocalization of exciton and higher lowering of energy of transiting vibrational levels in excited states [11].

The PL emission spectra were analyzed in more

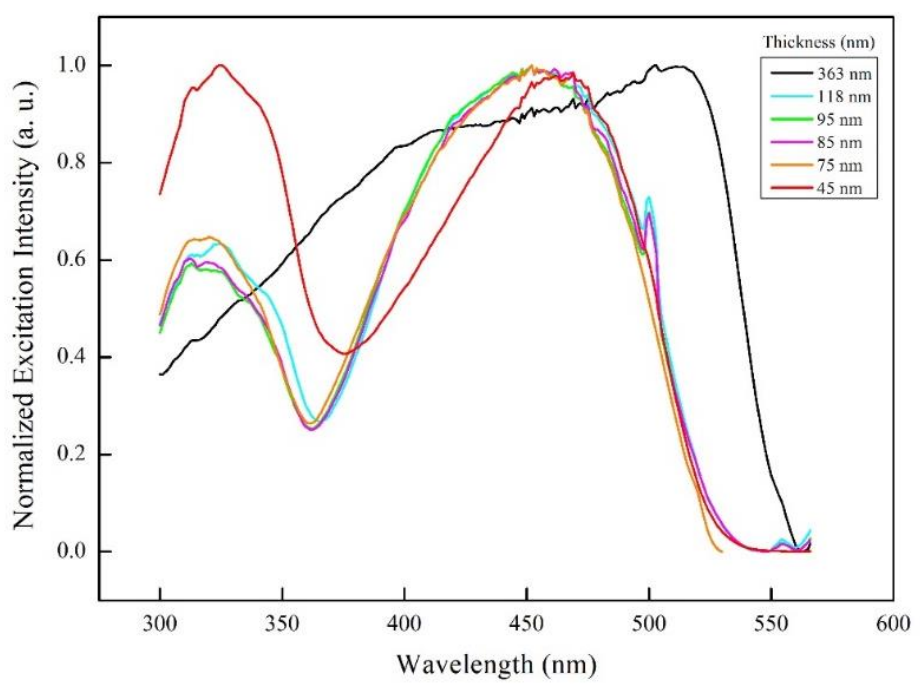

Figure 3 Excitation spectra of F8BT with different thicknesses on silicon substrates $\lambda_{\mathrm{em}}=576 \mathrm{~nm}$. detail. We introduced the ratio of spectral intensities of 0-0 and 0-1 transitions, IO-0 PL / / $0-1$ PL. The dependence of this ratio is shown in Figure 4 . It is clearly seen that the ratio is steeply decreasing with increasing thickness to the thickness about $120 \mathrm{~nm}$. For the samples with higher thickness, the ratio is close to value 1 , for extra thick sample $(360 \mathrm{~nm})$, the ratio decreases below value 1 . 


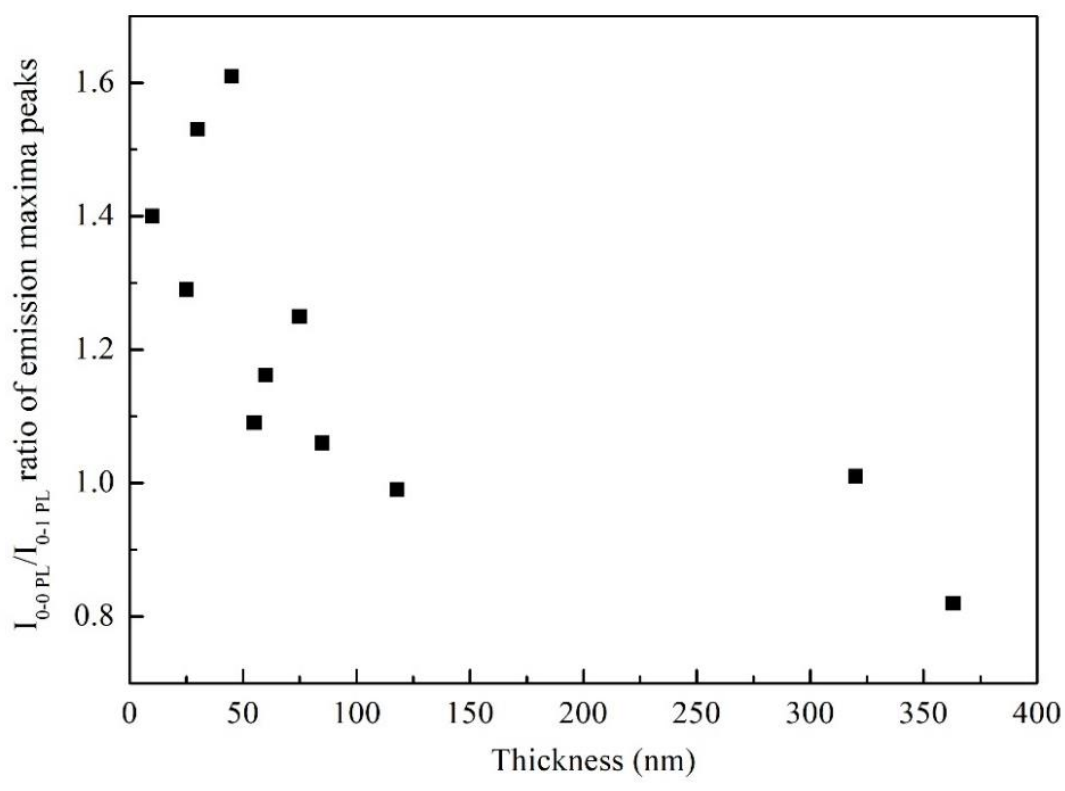

Figure 4 The ratio $(0-0) /(0-1)$ transitions dependence on thickness

This behaviour can reveal that the structure in thinner films (below $120 \mathrm{~nm}$ ) is prevailing organization of polymer chains in $\mathrm{J}$-aggregation because of this structural ordering is related to radiative transition from the lowest exciton state to the vibrationless ground state. On the other hand, in case of thicker films (over $120 \mathrm{~nm}$ ), the 0-1 transition starts predominate. This can indicate the structural ordering in more favorable $\mathrm{H}$-aggregation and lowering of potential energy [13,14].

\section{CONCLUSION}

In our contribution, we investigated the optical and optoelectrical properties of F8BT films depending on the films thickness. We analyzed the absorption and photoluminescence spectra. There is a correlation between the thickness of the films and manifestation of 0-0, 0-1 vibronic transitions that can stem from the intrachain (J-aggregates) and interchain ( $\mathrm{H}$-aggregates) structure of the films. We have argued that the structural ordering of the thin conjugated polymer film may vary with the film thickness in a non-trivial way and that it is allied to different levels of manifestation of nonlocalized (aggregate states) and localized (intrachain) transitions. Such findings can contribute to the utilization of conjugated polymers in polymer electronic, concretely in light emitting diodes, where the optical and optoelectrical properties play a most important role.

\section{ACKNOWLEDGEMENTS}

The authors are thankful for the financial support from the internal grant IGA/CPS/2020/003 from TBU in Zlin, the Czech Republic.

This work was also supported by the Operational Program Research and Development for Innovations cofounded by the European Regional Development Fund (ERDF) and the national budget of the Czech Republic, within the framework of the project CPS - strengthening research capacity

(reg. number: CZ.1.05/2.1.00/19.0409).

\section{REFERENCES:}

[1] FARIA, G.C., FARIA, R.M., R DEZEVEDO, E., VON SEGGERN, H. Molecular structure and dynamics of F8BTcorrelation with Opto-Electronic properties. In: IEEE 2011: 14th International Symposium on Electrets. Montpellier, France: 2011, pp. 101-102. 
[2] BURROUGHES, J. H., BRADLEY, D. D. C., BROWN, A. R., MARKS, R. N., MACKAY, K., FRIEND, R. H., BRUNS, P. L., HOLMES, A. B. Light-emitting diodes based on conjugated polymers. Letters to nature. 1990, vol. 347, pp. 539-541.

[3] YAN, X., JUN-BIAO, P., HONG-BIN, W., JIAN, W. Improved performance of polymer light-emitting diodes with an electron transport emitter by post-annealing. Journal of Chinese Physics Letters. 2009, vol. 26, no. 9, pp.0978014

[4] DONLEY, C. L., ZAUMSEIL, J., ANDREASEN, J. W., NIELSEN, M. M., SIRRINGHAUS. H., FRIEND, R. H., KIM, J. Effects of packing structure on the optoelectronic and charge transport properties in poly (9,9-di-n-octylfluorenealt-benzothiazole). Journal of the American Chemical Society. 2005, vol. 127, no. 37, pp. 12890-12899.

[5] PETROZZA, A., FAZZI, D., AVILOV, I., BELJONNE, D., FRIEND, R. H., KIM, J. Effects of polymer packing structure on photoinduced triplet generation and dynamics. Journal of Physical Chemistry C. 2012, vol. 116, no. 20, pp. 11298-11305.

[6] BERNARDO, G., FERREIRA, Q., BROTAS, G., DI PAOLO, R. E., CHARAS, A., MORGADO, J. Synergistic effect on the efficiency of polymer light-emitting diodes upon blending of two green-emitting polymers. Jornal of applied physics. 2010, vol. 108, pp. 0145031-8.

[7] SPANO, F. C., SILVA, C. H-and J-aggregate behavior in polymeric semiconductors. Jornal of Annual Review of Physical Chemistry. 2014, vol. 65, pp. 477-500.

[8] SPANO, F. C. The spectral signatures of frenkel polarons in $\mathrm{H}$ - and J-aggregates. Journal of Accounts of chemical research. 2010, vol. 43, no. 3, pp. 429-439.

[9] URBANEK, P., KURITKA, I., DANIS, S., TOUSKOVA, J., TOUSEK, J. Thickness threshold of structural ordering in thin MEH-PPV films. Journal of Polymer. 2014, vol. 55, no. 16, pp. 4050-4056.

[10] URBANEK, P., KURITKA, I., SEVCIK, J., TOUSKOVA, J., TOUSEK, J., NADAZDY, V., NADAZDY, P., VEGSO, K., SIFFALOVIC, P., RUTSCH, R, URBANEK, M. An experimental study of the structural ordering of the PTB7 polymer at a mespscopic scale. Journal of Polymer. 2019, vol. 169, pp. 243-254.

[11] URBANEK, P., KURITKA, I. Thickness dependent structural ordering, degradation and metastability in polysilane thin films: A photoluminescence study on representative $\sigma$-conjugated polymers. Journal of Luminescence. 2015, vol. 168, pp. 261-268.

[12] WANG, R., YANG, X., HU, S., ZHANG, Y., YAN, X., WANG, Y., ZHANG, C., SHENG, C. Effect of thermal annealing on aggregations on MEH-PPV films. The Journal of Physical Chemistry C. 2019, vol. 123, no. 17, pp. 11055-11062.

[13] SPANO, F. C., YAMAGATA, H. Vibronic Coupling in J-Aggregates and Beyond: A Direct Means of Determining the Exciton Coherence Length from the Photoluminescence Spectrum. The Journal of Physical Chemistry $B$. 2011, vol. 115, pp. 5133-5143.

[14] SPANO, F. C.,CLARK, J., SILVA, C., FRIEND, R. H. Determining exciton coherence from the photoluminescence spectral line shape in poly(3-hexylthiophene) thin films. The Journal of chemical physics. 2009, vol. 130, p. 074904. 